WellBeing International

WBI Studies Repository

1986

\title{
A Pivotal Year for Lab Animal Welfare
}

Constance Holden

Follow this and additional works at: https://www.wellbeingintlstudiesrepository.org/hensppite

Part of the Animal Experimentation and Research Commons, Animal Studies Commons, and the Laboratory and Basic Science Research Commons

\section{Recommended Citation}

Holden, C. (1986). A pivotal year for lab animal welfare. Science, 232, 147-151.

This material is brought to you for free and open access by WellBeing International. It has been accepted for inclusion by an authorized administrator of the WBI Studies Repository. For more information, please contact wbisr-info@wellbeingintl.org.

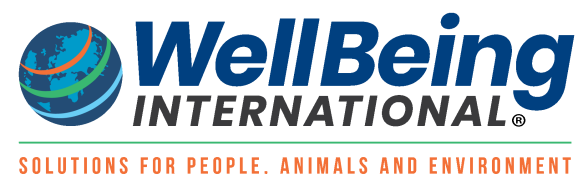




\title{
A Pivotal Year for Lab Animal Welfare
}

\author{
Tighter regulations, higher costs, and refined methodologies likely to lead to decreased animal use
}

Constance Holden

The past year has been a pivotal time for the animal welfare movement and a difficult one for scientists whose work involves experimental animals. Two major federal actions-amendments to the Animal Welfare Act of 1966 and revisions of the Public Health Service's (PHS) animal care guidelines-tighten standards for the humane use of animals and emphasize that the main responsibility for proper animal care lies at the institutional level.

The National Institutes of Health $(\mathrm{NIH})$ also acted to withhold research money from two institutions-the City of Hope Medical Center in Duarte, California, and the head trauma laboratory at the University of Pennsylvania - in the aftermath of raids by the Animal Liberation Front. And, in its first action under the new guidelines, in February the NIH suspended grants for research on vertebrates other than rodents at Columbia University (see box).

Compliance with the new rules will unquestionably be costly, particularly when combined with the darkening fiscal picture created by Gramm-Rudman and the indirect costs crunch. They are also likely to lead to a reduction in animal use at least in some institutions. But in general, the scientific community has accepted the changes as necessary.

All is not totally serene, however. Although moderate animal welfare groups accept the need for animals in research, there is a growing wing of the movement, made up of old-line antivivisectionists and new "animal rights" groups, who sec recent developments as only a step toward the real goal: total elimination of laboratory animals in research. These are the people who have staged laboratory break-ins, the latest being a raid last May at the University of California (Riverside) in which 467 animals were stolen.

It may be partly out of apprehension over future actions by these groups that the scientific community is rallying around to the new regulations. If scientists feel that the regulations are unduly intrusive, they are not saying so in public.

The major regulatory development is the move to locate oversight and monitoring of animal use and care firmly at the institutional level. To this end, the new PHS guidelines require every research institution to appoint an "institutional animal care and use committee." Every committee must have a veterinarian and an outside member on it. Research protocols must be reviewed by the committee to be sure they adhere to established standards. Committees must inspect facilities twice a year. Institutions must designate clear lines of authority for those involved in animal research, submit exhaustive information, on the animal care program, and supply a detailed "assurance" from facilities that have not been accredited by the American Association for Accreditation of Laboratory Animal Care (AAALAC). The accompanying NIH "Guide for the care and use of laboratory animals" specifies in excruciating detail requirements for personnel training, animal housing, and veterinary care.

The amendments to the Animal Welfare Act [sponsored by Representative George Brown (D-CA) and Senator Robert Dole (R-KS)] and passed as part of the 1985 farm bill, are designed to harmonize with the PHS guidelines and extend their coverage to other facilities. They cover all research facilities-about 2000 - that are engaged in interstate commerce. The amendments, which were the product of several 
years of intense lobbying and consideration of alternate bills, also mandate the establishment of animal care committees. The new law directs investigators to consider alternatives to animal use and specifies measures to minimize pain and distress. It also has two brand-new provisions-one requires exercise for laboratory dogs, the other [insisted upon by Senator John Melcher (D-MT)] says that primates must be furnished with a "physical environment adequate to promote" their "psychological well-being." This last vague provision could prove quite troublesome. Its official meaning is yet to be determined by the Department of Agriculture which is supposed to issue regulations on the act by the end of this year.

According to a recent report from the Office of Technology Assessment (OTA), on "Alternatives to Animal Use in Research, Testing, and Education," the revised Animal Welfare Act and the new PHS policy, taken together, "bring the overwhelming majority of experimental-animal users in the United States under the oversight of a structured, local review committee."

It is impossible as yet to assess the impact of the regulatory changes on the cost of doing research. Over half of the $\mathbf{8 0 0}$ or so institutions getting PHS funds already had animal care committees, but many have not been particularly active. About half the facilities have AAALAC accreditation according to William Gay of $\mathrm{NIH}$, and many more will probably seek it.

The National Association for Biomedical Research, according to its director Frankie L. Trull, believes that the costs of bringing facilities up to snuff--not to mention the increased costs for staffwork for animal care committees-may compel some smaller universities to get out of the animal business altogether. "We are seriously concerned that research institutions may be reaching the point where research will be sacrificed for economic reasons," she says. To many observers, the recent crackdown on Columbia University was a significant indication that $\mathrm{NIH}$, at least, intends to interpret its standards rigorously. "We were all [happily] shocked," comments John McArdle of the Humane Society of the United States.

A greater threat to research may be posed by the increasing volubility of animal activists. "Universities can only take so much PR heat," says Trull-ultimately, some may count the benefits of obscurity to be greater than the potential benefits of a research project that some animal rights group wishes to halt. If universities succumb to this kind of pressure, "an awful lot of research is not going to get done."

There is considerable debate over just how many laboratory animals are used in the United States today. The best guess from OTA, based largely figures from the Animal and Plant Health Inspection Service (APHIS) of the Department of Agriculture, is that between 17 and 22 million vertebrates are used for research each year, about $70 \%$ of them rats and mice. However, the Animal Welfare Act specifically excludes rats, mice, and birds, and reporting these species on the APHIS forms is voluntary. Other groups, such as the Humane Society, put the figure closer to 60 million-including animals bred for research but not used. OTA's Gary Ellis says that it is impossible to guess how many animals have not been accounted for in various reporting schemes. The National Academy of Sciences (NAS) hopes to supply more definitive figures in the current survey by its Institute for Laboratory Animal Resources (ILAR), which covers all facilities using vertebrate species.

There is evidence that animal use has been on the decline-chiefly for economic reasons-for some time. According to ILAR, total acquisitions among federal grantees dropped from 33.4 million in 1968 to 19.9 million in 1978.

Animal rights activists are now suggesting that the number can be drastically reduced with the introduction of alternatives to animals. These are commonly defined as the "three R's": replacement of animals with in vitro cultures, lower organisms, and nonanimal models; refinement of methodologies so as to reduce animal pain and stress; and reduction of the number of animals used in a test. McArdle 
claims, for example, that 80 to $90 \%$ of animal use could be curtailed immediately and the rest by the end of the century.

In fact, the picture is far too complex and fraught with uncertainty for any authoritative projections to be made. Animal advocates tend to blur the line between the use of animals in testing and their use in basic research, although the two uses are in many ways quite separate in their problems and prospects. Money problems are nowhere near as severe in private industry, where most toxicity testing occurs, as they are in academia, the locus of basic research. Animal use accounts for a minuscule proportion of the costs in industry.

It is true that in toxicity testing, significant advances have been made in the past few years in the direction of refining research methodology and the use of in vitro and mathematical models. Short-term toxicity testing has been where most of the progress has occurred-particularly with regard to the Draizc eye irritation test and the LD50 (lethal dose that will kill $50 \%$ of the test population). While trends in academic research have largely been in response to financial pressures, social pressures have had a dramatic effect in industrial testing, particularly in well-known consumer products such as cosmetics and household cleansers. Companies that a few years ago regarded research on alternatives as somewhat offbeat are now trumpeting their various initiatives and boasting of substantial reductions in animal use.

The rapidity with which this has all come about can in large measure be traced to the activities of one man: Henry Spira, a New York activist who in 1980 organized an anti-Draize campaign that stirred widespread public response. In swift succession, several new research programs were set up, notably one at Rockefeller University, subsidized by $\$ 1.25$ million from Revlon, and the Center for Alternatives to Animal Testing at Johns Hopkins University, launched with a \$2.1 million grant from the Cosmetics, Toiletry and Fragrance Association.

The classic LD50 test has now been virtually eliminated in favor of tests using judiciously selected dosages on fewer animals. A cosmetics association membership survey last year, for example, revealed that there had been a 75 to $90 \%$ reduction of animal use in oral toxicity tests. Although there is no in vitro substitute for the LD50, Kurt Enslein of Health Designs, a private firm in Rochester, New York, has developed a computer program to screen new chemicals that contains the results of over 6000 LD50 tests.

The Draize test is still widely used, although usually in a modified form which entails testing much weaker solution on rabbits' eyes. Procter and Gamble reported at a recent meeting of the Toxicology Forum that the "low volume" rabbit test is more predictive than the Draize test itself. At least a dozen in vitro alternatives to the Draize-ranging from cell cultures to whole rabbit eyes to testing substances on chick embryo membranes-are now under active investigation.

Alan Goldberg, head of the Johns Hopkins center, says he believes there are now enough potential alternatives for a full-scale validation study and is working on a report, a "critical evaluation of eye irritancy testing," to be ready next summer. He estimates that it will take 5 or 6 years to validate a battery of tests-validated against data from accidental human exposures—and get it widely adopted by industry.

Goldberg says progress has been so rapid that the time is ripe to address the "next big issue"—chronic toxicity, including carcinogenicity. The Ames test, based on Salmonella bacteria, has long been in use for screening chemicals for possible carcinogenicity, but not until recently have investigators considered that in vitro techniques could be adapted to long-term studies.

In contrast to testing, the sprawling enterprise of basic research is an area about which it is difficult to make generalizations. Spira thinks "basic researchers still have a fortress mentality." The OTA report 
states, however, that "it is not clear whether targeted funding efforts would produce alternatives faster than they are already being devised." Developing replacements in particular, it says, "is far more likely to be incidental than targeted."

Nonmammalian models, such as the aplysia, the squid, and the horseshoe crab, have become very popular with neuroscientists, but the choices have been dictated by science and practicality, not by the urge to replace mammals. When it comes to the deliberate development of alternatives, reduction and refinement (rather than replacement) appear to hold the main promise in the short term. Some of the reduction is driven purely by economic considerations. But refinements have been taking place on many levels, such as new instrumentation which makes possible painless and noninvasive animal procedures. The main thrust in basic research is to squeeze more out of the same amount of data by refinements in methodology, such as increased sophistication in statistics, better selection of models, reduction in control groups, and the sharing of animals and tissue samples.

It may be that the greatest advances could be made in more complex and comprehensive information systems-resulting in the reduction of duplicative studies and extrapolations which could obviate the need for preliminary experiments as well as suggest useful models on the primitive end of the phylogenetic chain. The OTA report supports the idea of a computer-based registry-including data on studies that show negative results-but warns that it would be a huge undertaking.

The more moderate branch of the animal welfare movement appreciates the complexity of the problems in developing alternatives. Christine Stevens, founder of the Animal Welfare Institute (who is credited as being a major force $m$ getting the Animal Welfare Act amended), agrees that the real promise in the near future is in refining methodologies, getting researchers better trained in the use of animal models, and improving information systems.

The revised Animal Welfare Act provides legislative basis for what could become a major information resource by directing the National Agricultural Library to provide a new information service on improved methods of animal experimentation with the help of the National Library of Medicine. However, money for this project would presumably come from APHIS, which would need a dramatically expanded budget to do it.

With questions of proper animal care now resolved, at least on paper, the most significant public policy question probably relates to the role of the federal government in encouraging the development and use of alternatives.

The government does not have targeted programs for research on alternatives, but there is some federal activity in the field of testing. For example, the National Toxicity Program, through the National Institute for Environmental Health Sciences, has spent about $\$ 70$ million over the past 5 years to lay a basis for validation of in vitro tests. The National Cancer Institute is putting several million dollars into work on in vitro models for carcinogenesis. And the Environmental Protection Agency plans to spend $\$ 1.5$ million to validate structure activity relationships, a computerized method for screening chemicals.

The main administrative focus for encouraging work on alternatives is in NIH's new Biological Models and Materials Resources Section within the Division of Research Resources. Its director, James Willett, is in charge of formulating a plan for NIH, due in October, which will be largely based on an NAS report, "Models for Biomedical Research: A New Perspective," issued last spring (Science, 21 June 1985, pp. 1412-1413). 
As for immediate goals, the research community and the mainstream of the animal welfare community appear to be willing to work together on one, which is to get APHIS adequately enforced and funded. Inspection of laboratories covered by the

Animal Welfare Act has always been a minor APHIS duty. A report last year by the General Accounting Office revealed that inspections were infrequent (the new legislation mandates twice yearly inspections) and that its veterinarians were poorly trained in laboratory animal care. The inspection budget has limped along at about $\$ 4.8$ million a year, and the President's budget regularly calls for that to be zeroed outthe idea being that local agencies and humane groups can do the job.

Richard Rissler of APHIS says inspections have increased since the heat has been on and that inspectors are now getting training. But observers, while happy with the law now, are very concerned that it will not get beyond the stage of lip service. And if it does not, university laboratories are probably right to anticipate more "inspections" conducted by the Animal Liberation Front. Indeed, some are bracing for itGay says he has heard some universities have spent up to $\$ 100,000$ in the past 18 months on improved security measures.

New regulations notwithstanding, the animal rights forces continue to grow, fed by an enormous amount of publicity over the past year, including an article in Parade magazine which resulted in 10,000 letters to the Humane Society, and massive interest engendered by figures such as talk show host Phil Donahue and commentator Paul Harvey. McArdle says Humane Society membership has doubled over the past year to 450,000, and that most of the new members are animal rightists. People for the Ethical Treatment of Animals (PETA), the country's largest radical group, says its membership has quadrupled, to over 120,000 .

These activists want to eliminate all research that impinges on any animal's quality of life. They do not perceive that any trade-offs are necessary because they maintain that animal research has not made any contributions of consequence to human health. At the NAS meeting, for example, speakers claimed that there had been no progress for decades in the reduction of cancer or mental illness despite extensive animal research ("the health of the average citizen continues to decline," observed Dale Armon of Pet Rescue).

The use of animals in behavioral research-the area that offers the slimmest prospects for replacing whole animals - is particularly abhorrent to these groups. They cite, for example, experiments in "learned helplessness" (which have made a major contribution to the understanding of depression), which demonstrate that animals suffer far more stress when they have no control over the timing of a noxious stimulus (electric shock). Animal rightists also oppose using animals for research on substance abusethe attitude being that we know already that these things are bad, and we have no right to inflict disorders on healthy animals that they are not naturally prey to.

The other major focus (outside of toxicity testing) is the use of animals in trauma research. The University of Pennsylvania shut down its project using baboons to study head trauma after a highly publicized 1984 break-in. Activists have also succeeded in getting the Department of Defense to stop using cats and dogs for training in the treatment of wounds. More recently, in January, animal activists helped sabotage a plan by University of Florida researchers who wanted to use dogs to test the Heimlich maneuver on drowning victims - a technique they suspect is ineffective. PETA staged a demonstration and the researchers called off the experiment, explaining that it did not look as though medical groups planned to endorse the technique anyway. 


\section{Centers Targeted by Activists}

Here are how things stand now at universities, whose care policies have, with help from animal liberationists, drawn the attention of the National Institutes of Health:

- University of Pennsylvania: Animal liberationists staged a raid in May 1984 in which they trashed a laboratory at the Head Injury Clinical Center where baboons were being subjected to whiplash injuries, and made off with extensive videotapes of the experiments. In July 1985, following a 4-day PETA sit-in at $\mathrm{NIH}$, the grant was suspended, reportedly on the grounds that there was insufficient supervision and training of the researchers. In November; NIH announced there would be no new grants on vertebrate animals to the university until a new assurance based on the revised PHS guidelines had been approved. Ongoing grants are not affected.

The university decided to shut down the primate lab, and the researchers involved are now pursuing their investigations on other animals, such as squid and guinea pigs.

The new assurance statement was submitted in December, and vice provost for research Barry Cooperman says early reinstatement is hoped for, in which case only about $\$ 2$ million in grants will have been affected. The university is also speeding up renovation of its animal facilities, which will cost about $\$ 5$ million.

Despite the lurid publicity attendant on the baboon tapes-which have been shown on all the major networks and in several countries-Cooperman says NIH did not have any problems with the research methodology. As for the trauma to the university, Cooperman says "the lab shutdown is not the major thing." The major thing is that the episode has "focused the university's attention" and gotten it to "address the issue in very concrete terms." He does feel, though, that NIH "has come down too harshly -it didn't have to suspend our new grants or the Columbia grants."

- City of Hope Medical Center in Duarte, California: Members of the Animal Liberation Front broke into the Beckman Research Institute in December 1984, destroying equipment and carrying off some animals. Their primary focus was a research project testing tobacco carcinogens in dogs. The Public Health Service asked for an evaluation of the animal care program which was produced in July 1985, documenting some deficiencies in facilities and veterinary oversight. NIH responded by suspending the animal care assurance and about $\$ 1$-million worth of grant money, according to executive medical director Charles Mittman. The center also acquiesced to a $\$ 12,000$ fine from the Department of Agriculture.

The center is now about to submit a revised assurance. It is fixing up temporary facilities and a new $\$ 3$-million vivarium is planned to be completed in 3 years. All this was planned but has been "accelerated by the sequence of events," says Mittman. Asked if he thought NIH had acted harshly, Mittman said, after a pause, "I understand their perspective."

- University of California, Riverside: In April 1985 members of the Animal Liberation Front carried off 467 research animals, stole documents; and vandalized facilities during a raid on the university's psychology and biology laboratories. Among the kidnapped was a stump-tailed macaque whose eyes had been sewn shut for research on the development of a device to help blind people navigate. PETA, which acts as a mouthpiece for the unidentified liberationists, claimed the animals had been subjected to painful and unnecessary experimentation and, in some cases, starved.

This February, however, after an 8-month investigation, $\mathrm{NIH}$ concluded that Riverside has an appropriate animal care program and that no corrective action is necessary. University officials said the raid resulted in $\$ 683,000$ worth of damage, lost animals, and lost research.

- Columbia University: Following an unannounced site visit in January, NIH suspended all grants involving research with vertebrates other than rodents at the university. The visit was triggered by an assurance statement submitted in December which documented various deficiencies in facilities, as well as complaints from animal activists, some of whom had entered in November to take pictures. According to Columbia spokesperson Mac Rudolph, the university already had plans to remedy the problems, which included inadequacies involving veterinary care, sterility in surgical facilities, housing for dogs under quarantine, and ventilation. The research in question involved several million dollars and 500 animals "maximum," says Rudolph. Some of the work is now being done in neighboring institutions that have proper assurances.

The university has set up an emergency animal care task force to coordinate immediate changes required to get funding back, which, it is hoped, will be in effect later in the spring. There are also long-range rehabilitation plans that will cost several hundred thousand dollars.

Although the Animal Liberation Front has staged a number of laboratory break-ins, there has been very little in the way of investigations or prosecutions. No leads are available from PETA, which claims to come by its information anonymously.

At Riverside, university police continue to investigate but no arrests have been made. In the City of Hope case, one man was arrested for possession of ten stolen rabbits. But in general, local police departments seem to find they have more pressing matters to attend to. 
Whether or not more raids occur, more political action can be expected directed at county and municipal governments. Animal groups will have what has become an annual show of force on 24 April for "World Laboratory Animals Day," when selected companies and universities will be taken to task for their animal practices. This year will see "more and more peaceful civil disobedience" according to Lori Gruen of PETA. "Scientists aren't going to be able to do anything without a public backlash." Among immediate goals on the activists' agenda are inclusion of animal advocates as the public members of institutional care committees, coverage of rats and mice by the Animal Welfare Act, and the elimination of "former pets" (pound animals) as research subjects.

There is little doubt that the combination of political pressure, financial stringency, and new and improved methodologies will result in the continued reduction of animal use at least in the near future. There is also little doubt that confrontations between the scientific community and the radical fringe of the animal welfare movement will continue.

\section{Recommended Citation:}

Holden, C. (1986). A pivotal year for lab animal welfare. Science, 232, 147-151. 